\title{
High quality development evaluation of western counties based on resources and environment synergy: a case study of Datong County, Qinghai Province
}

\author{
Jia $\operatorname{Li}^{1}$, Shengxi Ding ${ }^{2 *}$ \\ ${ }^{1,2}$ School of Finance and Economics, Qinghai University, Xining, Qinghai, China
}

\begin{abstract}
Resources and environment is the carrier and material basis of regional sustainable development. Regional high-quality development must adhere to the protection of resources and environment. Based on the investigation and empirical analysis of the current situation of industrial development in Datong County of Qinghai Province, this paper puts forward some countermeasures and suggestions to promote the coordinated high-quality development of resources, environment and industry in Datong County.
\end{abstract}

\section{Introduction}

High quality development is a kind of development direction and goal based on the foundation, controlling the overall situation and focusing on the future.The Fifth Plenary Session of the 19th CPC Central Committee clearly takes "high quality development" as one of the important guiding ideology of economic and social development during the 14th Five Year Plan period. In the new era, the county bears new functions, which is not only the support of rural revitalization, but also an important node to alleviate the "big city disease" and realize the coordinated development of urban and rural areas ${ }^{[1]}$.The foundation of high-quality economic development lies in the county, the short board lies in the county, and the potential lies in the county ${ }^{[2]}$. County economy has no unchangeable development ideas and unified development mode. It should be combined with its own regional industrial structure level, scientific and technological innovation ability and economic development level to clarify the new direction of economic development and find a suitable development mode ${ }^{[3]}$.

County economy is composed of small town economy and rural economy. It is a bridge between the city and the countryside.It is the economic region closest to the common people in real life. Therefore, the development of county economy is a major event related to the national economy and people's livelihood ${ }^{[4]}$.

\section{Datong County Industrial Development and the status quo of resources and environment}

\subsection{Characteristic agriculture and animal husbandry realize scale management}

The total agricultural output value reached 1.482 billion yuan, up 5\% year on year. We will vigorously develop high-quality and characteristic agricultural and livestock products, and increase the added value of agriculture by more than 4.6\%. 960 new land-saving solar greenhouses will be built. The results of agricultural scale operation are remarkable, with a moderate scale operation area of $260000 \mathrm{mu}$. 58 farmers' professional cooperatives, 49 family farms and 1200 new professional farmers were added. The qualified rate of sampling inspection of agricultural products reached $100 \%$. By 2019, the agricultural scale operation has achieved remarkable results, with a moderate land scale operation area of $273000 \mathrm{mu}$. 26 facilities agricultural parks have been built in the county, with a production area of $42800 \mathrm{Mu}$ and a production capacity of 123000 tons. The development level of vegetable industry in facilities is leading in the province; The number of large livestock was 189200 , and the level of proper scale management of the whole county's seed and breeding industry was significantly improved.

\subsection{Improving the quality and efficiency of County Industrial Development}

In 2019, the industrial added value will reach 3.926 billion yuan, an increase of 5\%. 280 new enterprises of various types were added, and 5 Enterprises above 
designated size were cultivated. In 2019, the total industrial output value of the county reached 22.902 billion yuan, an increase of 7.181 billion yuan compared with 15.721 billion yuan in 2010 , and the average annual growth rate from 2016 to 2019 reached 5\%. The industrial added value of the whole county reached 11.203 billion yuan, with an average annual growth of $4.35 \%$. The proportion of the industrial added value in the national economy of the whole county has been maintained at about $60 \%$, and the industrial status has become increasingly prominent. Although the growth rate of industrial added value has slowed down year by year, it is still higher than the national average.

\subsection{The development of modern service industry highlights competitive advantages}

In 2019, the GDP of Datong County will reach 11.211 billion yuan, and the output value of service industry will reach 3.499 billion yuan, with a year-on-year growth of $4.26 \%$, accounting for $31.21 \%$ of GDP, and the contribution rate to GDP growth will be $31.92 \%$, which optimizes the economic structure of Datong. Deepen the establishment of national e-commerce comprehensive demonstration county in rural areas, build four Township logistics distribution points, including logistics distribution center and Chengguan, 170 rural e-commerce service stations (points), healthy development of real estate, finance, insurance, intermediary and other modern service industries, and 349 financial service points in the county. In 2019, it will receive 2.959 million tourists and achieve tourism revenue of 860 million yuan, with a year-on-year growth of $15 \%$ and $26 \%$.

\section{Dynamic analysis of industrial development in Datong County}

\subsection{Analysis on the evolution of industrial structure}

Industrial structure is the production, technology and economic connection among industries formed in the process of social reproduction. County industrial structure refers to the composition of all kinds of industries in the county economy and the relationship between the quantity and quality ${ }^{[5]}$.

Table 1 GDP and GDP composition of Datong County from 2000 to 2019

\begin{tabular}{|c|l|l|c|c|c|c|c|}
\hline $\begin{array}{c}\text { parti } \\
\text { clar } \\
\text { year }\end{array}$ & GDP & $\begin{array}{c}\text { Adde } \\
\mathrm{d} \\
\text { value } \\
\text { of } \\
\text { prima } \\
\text { ry } \\
\text { produ } \\
\text { ction }\end{array}$ & $\begin{array}{c}\text { Adde } \\
\text { value } \\
\text { of } \\
\text { secon } \\
\text { dary } \\
\text { indust } \\
\text { ry }\end{array}$ & $\begin{array}{c}\text { Add } \\
\text { ed } \\
\text { valu } \\
\text { e of } \\
\text { terti } \\
\text { ary } \\
\text { indu } \\
\text { stry }\end{array}$ & $\begin{array}{c}\text { Prop } \\
\text { ortio } \\
\text { n of } \\
\text { prim } \\
\text { ary } \\
\text { prod } \\
\text { uctio } \\
\text { n }\end{array}$ & $\begin{array}{c}\text { Propo } \\
\text { rtion } \\
\text { of } \\
\text { secon } \\
\text { day } \\
\text { indust } \\
\text { ry }\end{array}$ & $\begin{array}{c}\text { Propo } \\
\text { rtion } \\
\text { of } \\
\text { tertiar } \\
\text { y } \\
\text { indust } \\
\text { ry }\end{array}$ \\
\hline 2000 & 21.4 & 2.6 & 14.9 & 3.9 & 12.15 & 69.63 & 18.22 \\
\hline 2001 & 22 & 2.8 & 14.9 & 4.3 & 12.73 & 67.73 & 19.55 \\
\hline 2002 & 24.6 & 2.9 & 16.9 & 4.8 & 11.79 & 68.70 & 19.51 \\
\hline 2003 & 30.9 & 3.1 & 22.8 & 5 & 10.03 & 73.79 & 16.18 \\
\hline
\end{tabular}

\begin{tabular}{|l|l|l|l|l|l|l|l|}
\hline 2004 & 36.9 & 3.3 & 28.2 & 5.4 & 8.94 & 76.42 & 14.63 \\
\hline 2005 & 43.7 & 3.6 & 34.4 & 5.7 & 8.24 & 78.72 & 13.04 \\
\hline 2006 & 58 & 3.8 & 47.9 & 6.3 & 6.55 & 82.59 & 10.86 \\
\hline 2007 & 66.2 & 4.8 & 53.9 & 7.5 & 7.25 & 81.42 & 11.33 \\
\hline 2008 & 67.5 & 6.6 & 52.3 & 8.6 & 9.78 & 77.48 & 12.74 \\
\hline 2009 & 63.4 & 6.7 & 47.1 & 9.6 & 10.57 & 74.29 & 15.14 \\
\hline 2010 & 80.9 & 8.5 & 61.5 & 10.9 & 10.51 & 76.02 & 13.47 \\
\hline 2011 & 91.3 & 9.8 & 68.6 & 12.9 & 10.73 & 75.14 & 14.13 \\
\hline 2012 & 98.3 & 11.2 & 72.2 & 14.9 & 11.39 & 73.45 & 15.16 \\
\hline 2013 & 105.7 & 13.1 & 75.5 & 17.1 & 12.39 & 71.43 & 16.18 \\
\hline 2014 & 106 & 13.8 & 73.7 & 18.5 & 13.02 & 69.53 & 17.45 \\
\hline 2015 & 97.8 & 13.7 & 63.9 & 20.2 & 14.01 & 65.34 & 20.65 \\
\hline 2016 & 86.3 & 13.5 & 45.9 & 26.9 & 15.60 & 53.20 & 31.20 \\
\hline 2017 & 100.3 & 16.1 & 53 & 31.2 & 16.12 & 52.84 & 31.11 \\
\hline 2018 & 107.6 & 17.7 & 56.3 & 33.6 & 16.47 & 52.30 & 31.30 \\
\hline 2019 & 112.1 & 19.7 & 57.4 & 35.0 & 17.60 & 51.20 & 31.20 \\
\hline
\end{tabular}

The proportion unit is $\%$, and the output value unit is 100 million yuan. It can be seen from table 1 that the industrial structure of Datong County will change from $12.15: 69.63: 18.22$ in 2000 to $17.60: 51.20: 31.20$ in 2000-2019. The added value of primary industry in Datong county increased from 260 million yuan in 2000 to 1.97 billion yuan in 2019 , with an average annual growth of $34.6 \%$. The development of the primary industry can be divided into two stages, the first stage (2000-2006) showed a downward trend, and then an upward trend.

The added value of the secondary industry also increased rapidly, from 1.49 billion yuan in 2000 to 5.74 billion yuan in 2019, with an average annual growth of $15.01 \%$. The development of the secondary industry can also be divided into two stages. In the first stage (2000-2006), the proportion of the added value of the secondary industry in GDP increased, and then decreased. From 2000 to 2019, the proportion of added value of the secondary industry in GDP has always been in the first place. From 2000 to 2019 , the proportion of added value of the secondary industry in GDP has always been in the first place.

The added value of the tertiary industry increased from 390 million yuan in 2000 to 3.5 billion yuan in 2019 , with an average annual growth rate of $41.97 \%$. At the same time, the proportion of GDP rose from $18.22 \%$ to $31.20 \%$. The development of the tertiary industry can also be divided into two stages. From 2000 to 2006, the proportion of the tertiary industry in GDP showed a downward trend, but fluctuated. From 2006 to 2019, the proportion of added value of the tertiary industry showed an upward trend.

\subsection{Analysis of employment structure}

With the development of economy, that is, with the improvement of per capita national income level, the workers first transfer from the primary industry to the secondary industry. When the per capita national income level further improves, the labor force will transfer to the tertiary industry. People call this Law of industrial structure change caused by per capita income change "petty Clark theorem" ${ }^{[6]}$. 
Table 2 Composition of employees in Datong County from 2000 to 2019

\begin{tabular}{|c|c|c|c|}
\hline $\begin{array}{c}\text { particular } \\
\text { year }\end{array}$ & $\begin{array}{c}\text { Employment } \\
\text { proportion of } \\
\text { primary } \\
\text { industry }\end{array}$ & $\begin{array}{c}\text { Employment } \\
\text { proportion of } \\
\text { secondary } \\
\text { industry }\end{array}$ & $\begin{array}{c}\text { Employmen } \\
\text { t proportion } \\
\text { of tertiary } \\
\text { industry }\end{array}$ \\
\hline 2000 & $65.08 \%$ & $18.27 \%$ & $16.64 \%$ \\
\hline 2001 & $64.70 \%$ & $17.80 \%$ & $17.50 \%$ \\
\hline 2002 & $58.48 \%$ & $21.03 \%$ & $20.49 \%$ \\
\hline 2003 & $56.97 \%$ & $22.95 \%$ & $20.09 \%$ \\
\hline 2004 & $49.65 \%$ & $28.63 \%$ & $21.72 \%$ \\
\hline 2005 & $50.51 \%$ & $29.56 \%$ & $19.93 \%$ \\
\hline 2006 & $40.87 \%$ & $37.36 \%$ & $21.78 \%$ \\
\hline 2007 & $39.51 \%$ & $37.49 \%$ & $23.01 \%$ \\
\hline 2008 & $37.02 \%$ & $38.22 \%$ & $24.76 \%$ \\
\hline 2009 & $37.71 \%$ & $39.80 \%$ & $22.49 \%$ \\
\hline 2010 & $36.15 \%$ & $39.72 \%$ & $24.13 \%$ \\
\hline 2011 & $35.62 \%$ & $36.32 \%$ & $28.06 \%$ \\
\hline 2012 & $33.03 \%$ & $37.97 \%$ & $29.01 \%$ \\
\hline 2013 & $33.49 \%$ & $37.49 \%$ & $29.02 \%$ \\
\hline 2014 & $32.09 \%$ & $40.67 \%$ & $27.24 \%$ \\
\hline 2015 & $31.90 \%$ & $38.42 \%$ & $29.68 \%$ \\
\hline 2016 & $31.35 \%$ & $37.67 \%$ & $30.98 \%$ \\
\hline 2017 & $30.03 \%$ & $38.24 \%$ & $31.73 \%$ \\
\hline 2018 & $29.25 \%$ & $40.13 \%$ & $30.62 \%$ \\
\hline 2019 & $29.58 \%$ & $40.26 \%$ & $30.16 \%$ \\
\hline & & & \\
\hline
\end{tabular}

The trend of the proportion of employees in the three industries in Datong County is different from the change of the proportion of added value, which shows that the proportion of employment in the primary industry gradually decreases, while the proportion of employment in the secondary and tertiary industries increases. The employment structure changes from primary industry $>$ secondary industry $>$ tertiary industry in 2000 to secondary industry $>$ primary industry $>$ tertiary industry in 2019.

The analysis shows that the change of industrial structure in Datong County from 2000 to 2019 conforms to the "petty Clark" theorem. With the further improvement of per capita national income in Datong County, the proportion of employment in the primary industry gradually decreases, and the labor force transfers to the secondary and tertiary industries.

\subsection{Analysis on the change of comparative labor productivity}

Kuznets summed up: with economic growth, the relative national income of the primary industry is in constant decline; the relative national income proportion of the secondary industry is generally rising, but in the late industrialization period, especially in the post industrialization period, the relative national income of the secondary industry will decline in varying degrees; the relative national income of the tertiary industry is in continuous growth Rising trend ${ }^{[7]}$.

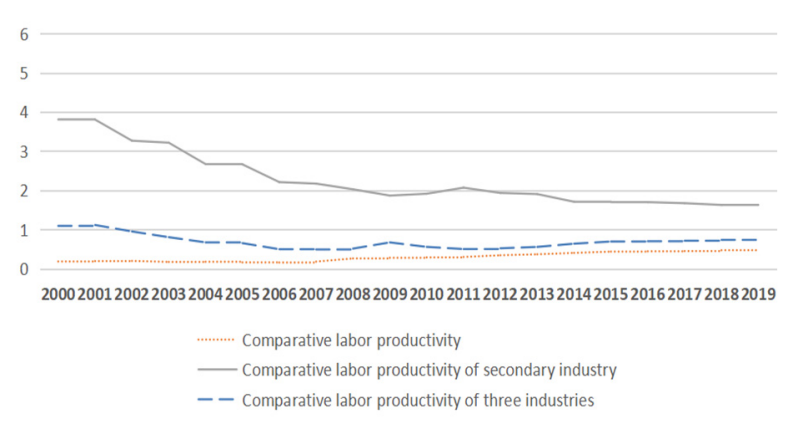

Fig.1. the change of labor productivity of Datong County from 2000 to 2019

As can be seen from Figure 1, the comparative labor productivity of the primary industry in Datong County from 2000 to 2019 is less than 1, the comparative labor productivity of the secondary industry is greater than 1 , the comparative labor productivity of the tertiary industry is greater than 1 from 2000 to 2001, but the comparative labor productivity is less than 1. Overall, the comparative labor productivity of the second industry is the highest, followed by the third industry, and the first industry is the lowest. And the secondary and tertiary industries are on the decline, while the primary industry is on the rise. The reason why the tertiary industry does not conform to Kuznets' rule of thumb is that in the tertiary industry, the traditional service industry dominated by wholesale and retail trade and catering industry still occupies a dominant position. These industries absorb more employment, but their output value is not as high as modern service industry.

To sum up, the industrial structure of Datong County from 2000 to 2019 does not show the law described by Kuznets.

\subsection{Analysis of urban and rural dual structure}

The urban-rural dual economic structure generally refers to the coexistence of urban economy characterized by socialized production and rural economy characterized by small-scale production. Binary contrast coefficient is one of the main measurement indexes of binary economic structure. The larger the binary contrast coefficient is, the smaller the difference between the two sectors is; on the contrary, the greater the difference between the two sectors is. Theoretically, the maximum value of binary contrast coefficient is 1 , but it is usually less than 1.

Calculation formula:

$B_{1}=\frac{G_{1} / G}{L_{1} / L}$
$B_{2}=\frac{G_{2} / G}{L_{2} / L}$
$R_{1}=\frac{B_{1}}{B_{2}}$

Where $\mathrm{G}$ is the total output value, $\mathrm{L}$ is the total labor force, $G_{1}$ is the output value of agricultural sector, $G_{2}$ is the output value of non-agricultural sector, $\mathrm{L}_{1}$ is the labor force of agricultural sector, $L_{2}$ is the labor force of 
non-agricultural sector. $\mathrm{B}_{1} \mathrm{~B}_{2}$ is the comparative labor productivity of the two sectors, and $R_{1}$ is the binary contrast coefficient.

Table 3 Binary contrast coefficient of Datong County from 2000 to 2019

\begin{tabular}{|c|c|c|c|}
\hline particular year & $\mathrm{B}_{1}$ & $\mathrm{~B}_{2}$ & $\mathrm{R}_{1}$ \\
\hline 2000 & 0.1867 & 2.5161 & 0.0742 \\
\hline 2001 & 0.1967 & 2.4726 & 0.0796 \\
\hline 2002 & 0.2016 & 2.1244 & 0.0949 \\
\hline 2003 & 0.1761 & 2.0906 & 0.0842 \\
\hline 2004 & 0.1801 & 1.8084 & 0.0996 \\
\hline 2005 & 0.1631 & 1.8541 & 0.0880 \\
\hline 2006 & 0.1603 & 1.5803 & 0.1015 \\
\hline 2007 & 0.1835 & 1.5333 & 0.1197 \\
\hline 2008 & 0.2641 & 1.4326 & 0.1844 \\
\hline 2009 & 0.2802 & 1.4358 & 0.1951 \\
\hline 2010 & 0.2906 & 1.4016 & 0.2074 \\
\hline 2011 & 0.3014 & 1.3865 & 0.2174 \\
\hline 2012 & 0.3450 & 1.3230 & 0.2608 \\
\hline 2013 & 0.3700 & 1.3173 & 0.2809 \\
\hline 2014 & 0.4057 & 1.2808 & 0.3167 \\
\hline 2015 & 0.4392 & 1.2627 & 0.3478 \\
\hline 2016 & 0.4476 & 1.2587 & 0.3556 \\
\hline 2017 & 0.4665 & 1.2298 & 0.3793 \\
\hline 2018 & 0.4702 & 1.2234 & 0.3843 \\
\hline 2019 & 0.4712 & 1.1963 & 0.3939 \\
\hline
\end{tabular}

It can be seen from table 3 that the dualistic contrast coefficient of Datong County is increasing in general and decreasing in some years, which indicates that with the implementation of the urban-rural overall planning policy, the dualistic economic structure of Datong County is constantly improving, but from the numerical point of view, the dualistic contrast coefficient of Datong County is always less than 0.5 , which indicates that the dualistic structure of Datong County is still very serious and the development of urbanization and industrialization is strict The emphasis is not coordinated.

\section{Conclusions and recommendations}

\subsection{Conclusions}

Based on the dynamic analysis of the county economy in Datong County, this paper finds that the GDP of the three industries is increasing year by year, the labor structure is transferring from the primary industry to the secondary and tertiary industries, the industrial structure of Datong county does not present the Kuznets law, and the dual structure is serious, and the development of urbanization and industrialization is seriously uncoordinated.

\subsection{Suggestions}

\subsubsection{Optimizing agricultural structure and protecting agricultural production resources}

We should further optimize the agricultural structure, stabilize grain production, tap the potential of grain production, promote new varieties of grain crops with high yield, high quality and high efficiency, and create demonstration projects with high yield, so as to improve the yield per unit area and ensure the steady growth of grain production. We should develop animal husbandry in agricultural areas, focus on the development of ecological recycling animal husbandry, accelerate the large-scale and intensive development, and improve the production capacity and market supply capacity of meat, eggs, milk and other animal products.

\subsubsection{Speed up industrial upgrading and develop recycling industry}

Accelerate the construction of environmental protection science and Technology Industrial Park, vigorously develop circular economy, and strive to build ecological industry. Efforts should be made to foster large enterprise groups with independent intellectual property rights, well-known brands, strong core competitiveness and obvious leading role. Support industry leading enterprises and advantageous backbone enterprises to become bigger and stronger through technological transformation, merger and reorganization, joint venture and cooperation, and give full play to the advantages of large enterprises and groups in terms of talents, technology, capital and brand.

\subsubsection{Developing modern service industry to reduce the pressure on resources and environment}

Actively develop the county life, productive service industry, and promote the development of modern service industry in the county. We should vigorously develop modern finance, science and technology services, transportation and other producer services, scientifically set up a statistical and evaluation index system, and enhance the function of producer services. We should reasonably set up the index system for the development of life service industry, and speed up the development of tourism industry, cultural industry, sports industry and other industries under the guidance of informatization, networking, quality and convenience.

\section{Acknowledgments}

This paper is one of the phased achievements of the general project of the National Social Science Fund "study on the dynamic mechanism and path selection of green development in Qaidam Basin" (19BMZ154).

\section{References}

1. Ma,H.J."The fourteenth five year plan" is the "golden age" of high-quality development of counties [J]. China information circles, 2020 (06): 41-44

2. Li,R.Q.Boosting high quality development of county economy with institutional supply [J]. China development observation, 2020 (24): 47-48 
3. Qin,X.New path of county economic development under Rural Revitalization [J]. Contemporary county economy, 2021 (03): 57-59

4. Long,K.Zhongmou County Economic Development Research [D]. Henan: Henan Normal University, 2015:8

5. Ding,S.X.Regional economics [M]. Xining: Qinghai People's publishing house, 2012:91

6. Li,Y.Industrial Economics [M]. Shenzhen: Shenzhen Haitian publishing house, 1993

7. Simon,K.Modern economic growth theory [M]. Beijing: Business Press, 1989 